\title{
Karabus saga raises wider issues
}

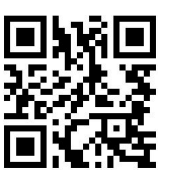

The lack of proper peerreviewed medico-judicial processes, which render healthcare workers vulnerable in foreign countries, the ethics of boycott politics, and the real political clout of top private business emerged as major themes in the 9-month saga of Professor Cyril Karabus.

The founder of Red Cross Children's Hospital's cancer unit in Cape Town, and respected veteran of public paediatric oncology and haematology, forcefully confined in the United Arab Emirates (UAE) - including 57 days in jail - underwent a bewildering 9-month trial (sans translator) for manslaughter and forgery charges. $\mathrm{He}$ finally boarded a flight home in mid-May after his acquittal, a failed State appeal and painfully drawn-out bureaucratic return clearance procedures. The charges related to his treatment of a 3-year-old Yemeni patient, Sara Al Ajaily, for pancytopaenia (a leukaemialinked condition), at the Shiek Khalifa Medical Centre in Abu Dhabi. The child died of a cerebral haemorrhage on 19 October 2002, and a grieving father and nurse together alleged - with an ultimately gross lack of substantiation - that Karabus failed to give her vital platelets and falsified the recording of her platelet administration after her death. Totally unaware that for 10 years he was regarded as a fugitive from UAE justice, and convicted in absentia of manslaughter and forgery and sentenced to 3 years in jail (plus a R250 000 fine), Karabus was en route home from his son's wedding in Canada when he was arrested at the Abu Dhabi International Airport during an overnight stopover on 18 August last year. The only prior inkling Karabus had that something might be amiss was when he boarded the Emirates Airline plane in Canada and ground staff told him there was an 'alert' on his passport, but failed, or were unable, to elaborate. After rapid liaison with his attorney in Cape Town and the deposit of R1 million in legal surety, a UAE lawyer took on his case and had the charges suspended - on condition he agree to a full retrial.

\section{SAMA waves the red flag}

Dr Mark Sonderup, Vice-Chairperson of the South African Medical Association (SAMA), which played hardball with the World Medical Association (WMA) to secure an unprecedented resolution warning healthcare workers off the UAE (SAMA called for a complete economic and healthcare worker

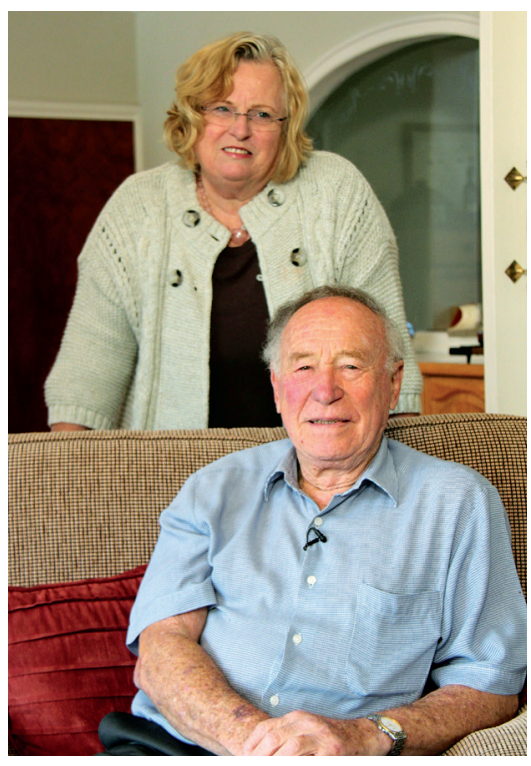

Professor Cyril Karabus back at home with his wife Jen (photo by Fran van Rooyen).

boycott of the UAE), says a core issue was lost in the media frenzy. This was the criminalisation of medical practice anywhere' (no automatic peer review mechanism to deal with the multi-faceted medical environment and complex nature of a job with 'so many variables'). Sonderup adds: 'The automatic criminalisation of any professional conduct is anathema to us. Even with our challenged judicial system here, the first charge if a child with advanced leukemia died from a cerebral bleed would not be manslaughter - and certainly not in absentia. At least our processes are correct (professional conduct hearings before the Health Professions Council (HPCSA)'s relevant professional body - which can forward the outcome of its hearings for criminal investigation if deemed necessary.' Sonderup says that, for the UAE, whose healthcare workforce is $93 \%$ foreign, to behave with such impunity (in the face of a global outcry from human rights and healthcare organisations) is either completely stupid or completely arrogant - if you're dependent on the rest of the world to run you, you can't behave like that'.

\section{Boycott 'selective and emotional' - ethicist}

The SAMA boycott kicked in with the UAElinked Africa Healthcare tradeshow in Gauteng from 6 - 8 May this year, with local healthcare regulators - the HPCSA withdrawing in solidarity. Some stakeholders argued this was inappropriate as the conference organisers were Swiss-based. One of the most vociferous critics of the conference boycott was Professor Sylvester Chima, Head of Bio and Research Ethics and Medical Law at the Health Sciences Faculty, University of KwaZuluNatal in Durban. He charged that SAMA doctors were 'being unethical, misinformed, misguided and therefore becoming emotional, unprofessional and applying double standards with or without being aware of it.' Chima said that none of the many big South African companies doing business in Dubai had 'been instructed or told to get involved in trying to secure the release of Cyril Karabus; neither have their businesses been boycotted. $\mathrm{He}$ said pressure should be applied across the board, not against one organisation which is simply carrying out its business like everyone else'. 'It will be a dark day for all if justice is allowed to be applied unequally, so that if you are a famous doctor and have friends in high places, then your case should be tried quickly without regards to due process, while if you are poor, or perhaps a sick child with cancer, then neither you nor your parents should be given all the benefits provided for in law, including the rights of appeal.

SAMA responded that the Karabus case was one of several involving healthcare professionals in the UAE, and repeating that the conference was organised from Dubai. Calling Chima's remarks 'startling, coming from an ethicist,' it said his comments showed he was out of touch with the realities of the case, especially the global outcry from the WMA, the BMA, the AMA (who complained to Secretary of State John Kerry), Amnesty International, Human Rights Watch and several others.

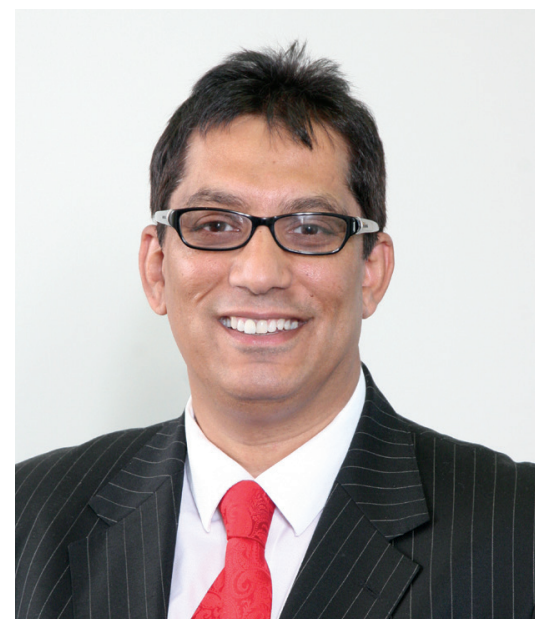

Dr Iqbal Surve. 
Compassionate colleagues transcend culture/religion

Two of several Muslim doctors outraged by the UAE's behaviour inadvertently fell under the media spotlight in their bids to help Karabus. Dr Asad Bhorat, a Soweto GP, walked out of the Africa Healthcare Conference where he was chairing a programme after the organisers refused to allow him to put a motion to the floor condemning the UAE's treatment of Karabus. Having originally helped to prepare the programme for the Family Practitioners section of the conference, Bhorat had just returned from a Gift of the Givers charity mission to war-torn Syria and was totally unaware of the boycott controversy. He told Izindaba that on learning of the boycott and with the organisers 'adamant' that they were Swiss-based with no UAE links, he 'decided to test them' by proposing his motion. 'They absolutely refused me permission, which pretty much exposed their interests, so I pulled out,' he said.

The other was philanthropist and founder of the Sekunjalo Group, Dr Iqbal Surve, whose historical business ties with the UAE Royal Family ultimately speeded up Karabus' acquittal and the grindingly slow bureaucracy clearing him to fly home. Surve flew twice to Abu Dhabi, the first time meeting with the Royal Family as part of a 3-person SA business delegation to complain about the 7-month inaction of the court's medical advisory committee (the committee met the next day and exonerated Karabus, resulting in his acquittal the following day). The second time was after the court dismissed an appeal by a seemingly obdurate prosecution which then dragged its heels in providing a written undertaking that it would not appeal a second time, effectively delaying his return by 2 extra months. Izindaba sources said Surve's second royal supplication followed Karabus' frustrated criticism of the UAE in a television interview that led to a fierce internal debate among the country's political 'hawks and doves', the former arguing for 'full application of the law (i.e. a second appeal)' and the latter (read: top Royal Family members) pleading for compassion.

\section{A life interrupted - wrapping up unfinished business}

Karabus, back in his Kenilworth home with his relieved but still-outraged wife Jen, was looking forward to the simple pleasures: 'gardening, walking on the mountain and doing the odd (local) locum, if it's on offer'. With a local State pension of R15 000 per month, he's putting off a decision on suing either the UAE or the hospital owners in favour of full recuperation, going for a check-up with his cardiologist (he has a stent and pacemaker), filling in his taxes and 'doing right' by his erstwhile UAE host of 7 months and compatriot, urologist Elwyn Buchel. He still has to 'balance the books' on R1 million in outstanding legal, transport and logistical costs. An international fundraising appeal and 2 of his children bonding their homes paid the initial legal bills of another R1 million. How much the fund will ultimately mitigate his financial worries (his 2002 UAE locum was meant to supplement his meagre State pension), only time and his paediatrician/fund-manager and daughter, Sarah, will eventually tell.

\section{Chris Bateman}

chrisb@hmpg.co.za

S Afr Med J 2013;103(7):442-443.

DOI:10.7196/SAMJ.7100 